\title{
Study on Influence of Water-cooled Stool During the Process of Unidirectional Solidification
}

\author{
Guangwu Ao ${ }^{1}$, Minggang Shen ${ }^{*}, 2$ Zhenshan Zhang ${ }^{1}$ and Xiaodong $\mathrm{Li}^{2}$ \\ ${ }^{1}$ School of Applied Technology, University of Science and Technology Liaoning, Anshan114011, China \\ ${ }^{2}$ School of Materials and Metallurgy, University of Science and Technology Liaoning, Anshan 114051, China
}

\begin{abstract}
A mathematical model for a unidirectionally solidified ingot cooled with a multi-set water-cooling system was established with ProCAST software. Temperature and heat flux fields in a $45 \mathrm{t}$ ingot during solidification under the influences of a traditional water-cooled stool and an improved one were predicted by using this model. The results of temperature distribution and heat flux field show that the proposed chassis cooling system can improve the vertical temperature gradient. Uniform columnar grains from the top to the bottom of the ingot were revealed by the modeling results indicating that improved mechanical properties of the cast product could be achieved.
\end{abstract}

Keywords: Flow field, steel ingot, temperature field, unidirectional solidification, water-cooled stool.

\section{INTRODUCTION}

Directional solidification has been widely used in manufacturing the advanced material with special orientation of internal structure and excellent performance. Generally speaking, there are three aspects in the production technology of directionally solidified ingots such as sidewall insulation, chassis cooling and liquid level. The sidewall insulation controls mold temperature gradient from the bottom to the top so that the solidification occurs only in one direction from the bottom to the top of the mold. In order to promote the directional solidification, it is also required to increase the bottom cooling as much as possible. Appropriate chassis cooling schemes will establish even nucleation of the ingot bottom that is in a uniform contact with the cooling chassis ensuring enhanced heat transfer to the chassis and thus uniform solidification.

Using a large and thick chassis and a chassis with forced cooling (usually using water) are common practices in directional solidification. Tamaguchi Miyuki et al. [1] consider that it is costly if, after service, the whole thick chassis is replaced with a new one and thus the whole thick chassis should be divided into two parts: an upper part and a lower part. Only the upper part after damage needs to be replaced. However, thermal resistances are easy to form between the two if they do not tightly contact with each other. Yuanyingshi et al. [2] think that in general directional solidification processes, the bottom of the ingot will have a reverse contraction, forming an air gap between the ingot and the chassis, which can significantly reduce the thermal conductivity between the chassis and the steel ingot, so that the height of directional solidification layer of the ingot becomes limited.

*Address correspondence to this author at the School of Materials and Metallurgy, University of Science and Technology Liaoning, Anshan 114051, China; Tel: 0412-5929545; Fax: 0412-5929341;

E-mail: lnassmg@163.com
According to the above-mentioned analysis on the previous work $[1,2]$, the authors proposed a new type of chassis with a multi-set water-cooling system to be used for directional solidification. Figs. (1 and 2) show the top-view of the new chassis geometry and its representation by a finite element model, respectively. The chassis is comprised of three blocks (cf., Fig. 1), each with an in-built snake-shaped water-cooling channel. Through controlling and optimizing the cooling intensity in different blocks of the chassis, a stronger cooling intensity in the center zone (B1) but a weaker cooling intensity in the outer zone (B3) can be achieved resulting in appropriate distributions of the cooling intensity consistent with air gap formation and thus yielding nearly uniform solidification in the vertical direction of the ingot and avoiding local contraction (buckling) in the ingot bottom. Furthermore, in order to optimize the chassis cooling parameters, a mathematical model was established to predict the temperature field and heat flux field inside a $45 \mathrm{t}$ heavy steel ingot and numerical simulations on the solidification of the ingot cooled with both the conventional water-cooled stool and the improved one were carried out, respectively.

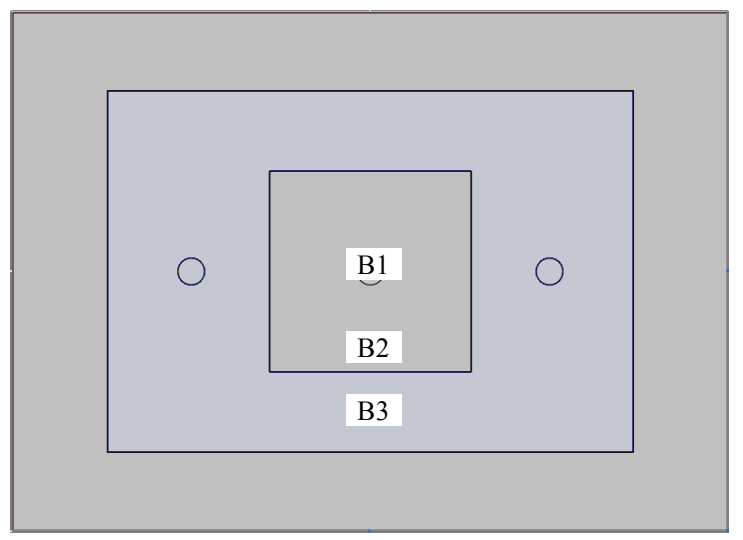

Fig. (1). Sketch of geometry of optimized water-cooled stool. 


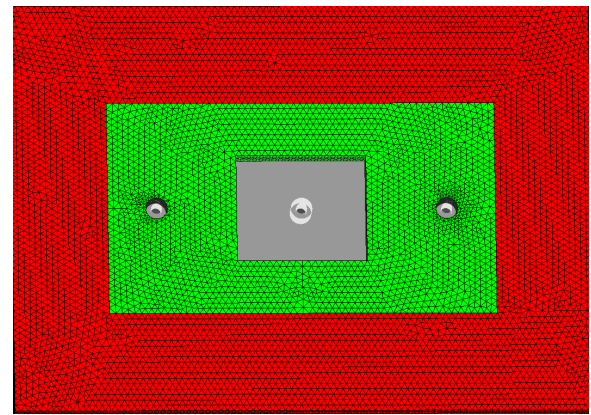

Fig. (1). Finite element model of optimized water-cooled stool.

\section{MATHEMATICAL MODELING}

\subsection{Basic Assumptions}

In order to mathematically model the process of directional solidification of a large (45 t) steel ingot, the modeling conditions should be set as close to the real process as possible. Nevertheless, considering the feature of unidirectional solidification of thick and wide steel ingot, it is difficult to take into account of every aspect of the solidification process. Therefore, appropriate assumptions and omissions should be made acceptable to the actual situation. In the present work, the mathematical model based on Finite Element Method was developed by using ProCAST software based on the following assumptions [3-6]:

1. The filling process of liquid metal is instantaneous and the solidification starts soon after that;

2. According to the viewpoint of E A Mizikar, heat transfer due to flow of liquid metal and solid metal grains is neglected, which is compensated by appropriately increasing thermal conductivity of the liquid metal;

3. Metal density is a constant;

4. The effective specific heat and the effective heat conductivity of the metal are adopted;

5. The materials involved in the simulations are isotropic;

6. Solidification takes place under equilibrium conditions;

7. The ingot deformation and volume change during solidification are ignored.

\subsection{Governing Equations}

The solidification process of liquid steel in a mold can be described by the following governing partial differential equations [7-9]:

\subsubsection{Equation of Mass Conservation:}

$\frac{\partial \rho}{\partial \mathrm{t}}+\frac{\partial(\rho u)}{\partial x}+\frac{\partial(\rho v)}{\partial y}+\frac{\partial(\rho w)}{\partial z}=0$

\subsubsection{Equation of Energy Conservation:}

$\rho \frac{\partial H}{\partial \mathrm{t}}=k\left[\frac{\partial^{2} T}{\partial x^{2}}+\frac{\partial^{2} T}{\partial y^{2}}+\frac{\partial^{2} T}{\partial z^{2}}\right]$

and

$$
H=\int_{0}^{T} C_{P} d T+L\left[1-f_{S}\right]
$$

where, $H$ is enthalpy at a point inside the ingot $(\mathrm{J} / \mathrm{kg}) ; \rho$ is density $\left(\mathrm{kg} / \mathrm{m}^{3}\right) ; C_{p}$ is heat capacity $(\mathrm{J} / \mathrm{kg} \cdot \mathrm{K}) ; k$ is material thermal conductivity $(\mathrm{W} /(\mathrm{m} \cdot \mathrm{K}))$; $\mathrm{T}$ is temperature $(\mathrm{K}), \mathrm{t}$ is time $(s) ; L$ is latent heat $(\mathrm{J} / \mathrm{kg})$; and $f_{s}$ is solid fraction.

The above equations coupled with the initial and boundary conditions are solved numerically using ProCAST, which constitutes a mathematical model to describe the solidification process of the ingot.

\subsection{Solution Conditions}

\subsubsection{Initial Conditions}

Because the solidification time is much longer than the filling time during the casting process, the effect of the filling process on the initial temperature field in the mold can be ignored. Therefore, the pouring molten steel temperature is set at $1560^{\circ} \mathrm{C}$. The baking temperature of ingot mold is 80 ${ }^{\circ} \mathrm{C}$ and the atmospheric temperature is $25^{\circ} \mathrm{C}$.

\subsubsection{Boundary Conditions}

Boundary condition of the third type is applied to the contact interface between the bottom of the ingot and the water-cooling chassis, whereas a boundary condition of the second type is assigned to the ingot center symmetrical planes and the outer surface of the insulated walls of the mold [10-13], i. e.,

on the top surface of the ingot: $k \frac{\partial T}{\partial z}=q$;

on the bottom surface of the ingot: $q=h\left(T_{b}-T_{f}\right)$;

on the ingot sidewall surfaces: $\frac{\partial T}{\partial x}=0$ and $\frac{\partial T}{\partial y}=0$;

and on the ingot center symmetrical planes: $\left.\frac{\partial T}{\partial x}\right|_{x=X / 2}=0$ and $\left.\frac{\partial T}{\partial y}\right|_{y=Y / 2}=0$

where, $X$ and $Y$ stand for the widths of the ingot's wide and narrow faces, respectively, and accordingly $\mathrm{x}=X / 2$ and $\mathrm{y}=$ $Y / 2$ represent the half thicknesses of steel ingot in $\mathrm{x}$ and $\mathrm{y}$ directions, respectively; $q$ is heat flow density (flux) from the top surface of the ingot $\left(\mathrm{W} / \mathrm{m}^{2}\right) ; h$ is heat transfer coefficient $\left(\mathrm{W} /\left(\mathrm{m}^{2} \mathrm{~K}\right)\right) ; T_{b}$ is the bottom surface temperature of ingot $(\mathrm{K})$; and $T_{f}$ is the temperature of cooling water $(\mathrm{K})$. 


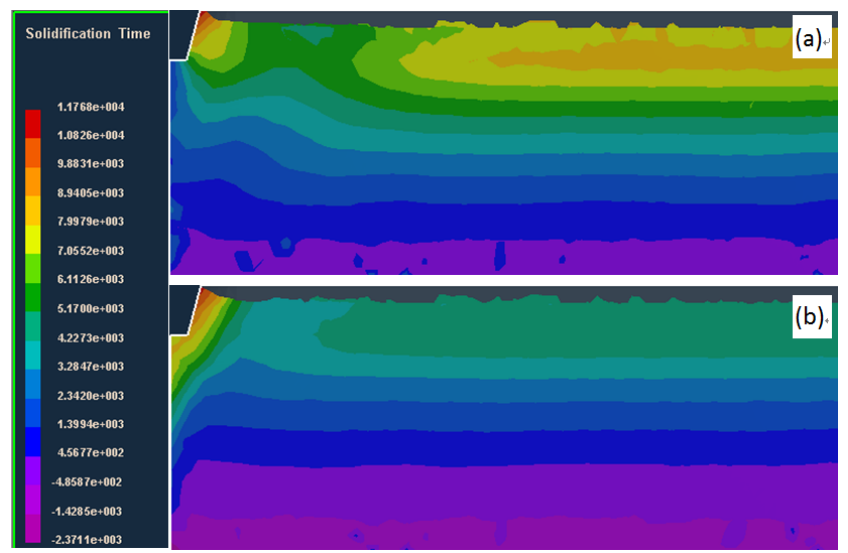

Fig. (3). Predicted temperature contours on a cross-sectional center symmetrical plane of directionally solidified ingots with (a) a traditional chassis cooling system and (b) an improved chassis cooling system.

The unidirectional solidification of the wide and thick steel ingot is treated as unsteady-state one-dimensional heat conduction in vertical $(\mathrm{z})$ direction. Therefore, the abovementioned initial conditions and three types of boundary conditions can be cast into the following general form:

$$
A_{T} T+B_{T} Q=C_{T}
$$

where, $T$ is the wall temperature $(\mathrm{K}) ; Q$ is the heat flux through the wall $\left(\mathrm{W} / \mathrm{m}^{2}\right)$; and $A_{T}, B_{T}$ and $C_{T}$ are constants to be determined based on the boundary conditions:

$A_{T}=1$ and $B_{T}=0$ refer to the boundary condition of the first type;

$A_{T}=0$ and $B_{T}=1$ set the boundary condition as the second type; and

$A_{T} \neq 0$ and $B_{T} \neq 0$ define the boundary condition of the third type.

For the boundary condition of the third type, $Q=h\left(T_{\mathrm{inf}}-\right.$ $T$ ) can be transformed into $h T+Q=h T_{\mathrm{inf}}$, with $A_{T}, B_{T}$ and $C_{T}$ being used to determine the boundary conditions of this kind.

The heat transfer coefficient of the traditional watercooled chassis is set as $5000 \mathrm{~W} /\left(\mathrm{m}^{2} \mathrm{~K}\right)$ and kept constant during numerical simulation process. For the new chassis with a three-block water-cooling system (cf., Fig. 1), constant heat transfer coefficients are set as $20000 \mathrm{~W} /\left(\mathrm{m}^{2} \mathrm{~K}\right)$ in $\mathrm{B} 1,10000 \mathrm{~W} /\left(\mathrm{m}^{2} \mathrm{~K}\right)$ in $\mathrm{B} 2$ and $5000 \mathrm{~W} /\left(\mathrm{m}^{2} \mathrm{~K}\right)$ in $\mathrm{B} 3$, respectively [14].

In addition, the liquid steel of grade Q235B was taken as the object of the present study. The solidus and liquidus temperatures of this grade steel are set as $1393{ }^{\circ} \mathrm{C}$ and 1520 ${ }^{\circ} \mathrm{C}$, respectively.

\section{SIMULATION RESULTS AND ANALYSIS}

Simulations of the solidification process of steel ingots can provide predictions on the temperature distribution in the ingot and heat flux to the chassis that can be used as a basis for evaluating the ingot quality and for avoiding formation of shrinkage holes, shrinkage pores, segregation and hot crack defects so as to guide the production and improve the quality of the ingot.
Fig. (3a and b) show the model predicted temperature distributions (contours) on a cross-sectional plane (center symmetrical plane) of $45 \mathrm{t}$ directionally solidified ingots cooled with a traditional chassis and an improved one, respectively. It can be seen from (Fig. 3) that, compared with (Fig. 3a), the solidification front depicted by (Fig. 3b) is much more smooth and uniform than that by Figs. (3a and $\mathbf{b}$ ) also indicates that the vertical temperature gradient in the ingot is increased and thus the grain orientation of the solidification structure is well controlled. Thus, these modeling results demonstrate that using a chassis with a multi-set water-cooling system and optimized cooling intensities, the quality of the unidirectionally solidified ingots can be significantly improved.

Fig. (4) shows model predicted heat flux vectors for $45 \mathrm{t}$ directionally solidified steel ingots with a conventional water-cooled stool (Fig. 4a) and an optimized water-cooled stool (Fig. 4b), respectively. From this figure we can see that in the ingot with an improved water-cooling system and insulated (hollow) lateral sidewalls the heat flux vectors are almost in one (vertical) direction perpendicular to the solidliquid interface (cf., Fig. 4b), whereas in the ingot with a traditional cooling chassis and sidewalls without insulating the heat flux vectors exhibit much more diverging with a noticeable amount of heat flowing into the sidewalls, as is seen from Fig. (4a). Therefore, the modeling results shown in (Fig. 4) also prove that with an optimized water-cooling chassis and hollow lateral sidewalls, the majority of the heat is transferred toward the water-cooling chassis so that the unidirectional solidification is greatly promoted.

Fig. (5) shows model predicted temperature, as a function of the solidification time, at a specific position on the outer sidewall of the molds with traditional and optimized watercooling chassis. The temperature sampling position is set at $\mathrm{x}$ $=1 / 2 X$ and $y=1 / 2 Y$ on the outer surface of the steel ingot molds. It can be seen from this figure that the sampling point temperature with the optimized multi zone cooling system is lower than that with the conventional one, which implies that more heat flows from the ingot toward the optimized watercooling chassis than toward the traditional water-cooling chassis. The modeling results shown in Fig. (5) further demonstrate the effectiveness of the new type of chassis with a multi-set water-cooling system and an optimized cooling 
intensity developed in the present work on improving the quality of unidirectionally solidified $45 \mathrm{t}$ large and heavy steel ingot.

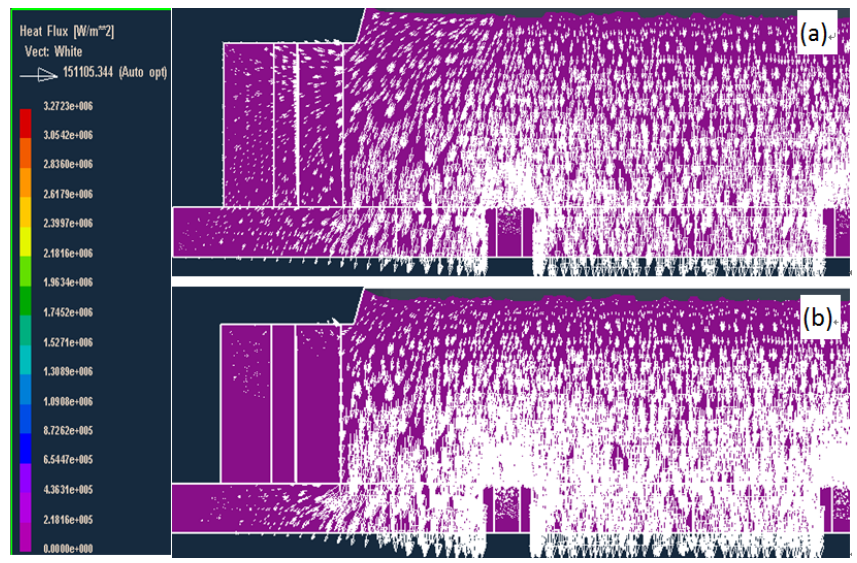

Fig. (4). Heat flux of unidirectionally solidified ingot with cooling system.

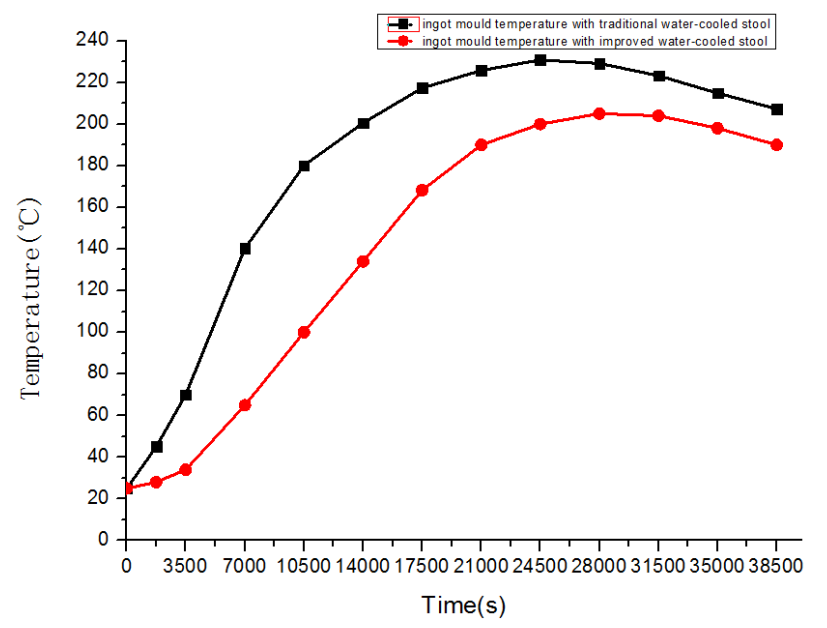

Fig. (5). Predicted time evolutions of temperature at a position $\mathrm{x}=$ $1 / 2 X$ and $y=1 / 2 Y$ on the outer surface of steel ingot molds with traditional and optimized water-cooled stool.

\section{CONCLUSION}

A new type of chassis, comprised of three water-cooling blocks, has been proposed for improving the quality of $45 \mathrm{t}$ unidirectionally solidified steel ingot. Mathematical modeling results demonstrate that the solidification front in the ingot with the new chassis with optimized cooling intensity is much more smooth and uniform than that with traditional water-cooling chassis.

The temperature field predicted by the mathematical model indicates that by using a chassis with multi-set watercooling channels and optimized cooling intensities the quality of the unidirectionally solidified steel ingots can be significantly improved.

The model predicted heat flux vector field and sidewall temperature further prove that with an optimized watercooling chassis combined with hollow lateral sidewalls, the majority of the heat is transferred toward the water-cooling chassis ensuring that the grain orientation of the solidification structure is well controlled and thus the unidirectional solidification is greatly promoted.

\section{CONFLICT OF INTEREST}

The authors confirm that this article content has no conflict of interest.

\section{ACKNOWLEDGEMENTS}

This work was supported by The Education Department of Liaoning Province Key Laboratory Project (No. 2008S122) and Metallurgical Engineering Laboratory of University of Science and Technology Liaoning, China.

\section{REFERENCES}

[1] Yamaguchi Miyuki. Zhao 61- 169138.

[2] Yuanyingshi. Public chartered Bulletin. Zhao 61- 42451.

[3] Jin HP, Li JR, Yu J, Liu SZ. Study of heat transfer coefficient used in the unidirectional solidification simulation based on orthogonal design. Rare Met Eng 2010; 39: 767-70.

[4] Garcia A, Prates M. Mathematical model for the unidirectional solidification of metals: I. cooled molds. Metallurg Mat Trans B 1978; 9: 449-57.

[5] Shin YH, Kang CS, Oh KH. A mathematical model of unidirectional solidification in cooled mold. Metals Mat Int 2000; 6: 189-94.

[6] Pan EN, Lim CS, Loper CR. Effects of solidification parameters on the feeding efficiency of Aluminum alloys. Trans Am Found Men's Soci 1990; 98: 735-46.

[7] Yang Q, Zhang Z. Numerical simulation of metal solidification and casting process. Hangzhou: Zhejiang University Press 1996; 13546.

[8] Liu B, Jing T. Simulation and quality control of casting process. Beijing: China Machine Press 2001; 105-26.

[9] Chen $\mathrm{H}, \mathrm{Li} \mathrm{H}$, Cao Y. Numerical simulation of casting solidification process. Chongqing: Chongqing University Press 1991; 95-106

[10] Vijayaram TR, Sulaiman S, Hamouda AMS, Ahmad MHM. Numerical simulation of casting solidification in permanent metallic molds. J Mat Proces Technol 2006; 39-3.

[11] Liu J, Li H, Jiang K. Numerical simulation on solidification process of large sized steel casting. Found Technol 2011; 32: 4435.

[12] Lü N, Jin Y, Li S, Xingang A, Xiaonguang Y. Numerical simulation on gradient cooling behavior of jumbo slab ingot plate. Chin Foundry 2013; 10(2): 87-91.

[13] Liu Z, Zhao Y, Zhang Y. The temperature field of large ingot solidification shrinkage prediction, calculation and osteoporosis. J Iron Steel Res 1993; 5: 23-32.

[14] Mizikar EA. Spray cooling investigation for continuous casting of billets and blooms. J Iron Steel Eng 1970; 7: 49-56. 